\title{
ANALYSIS OF DUPLICATION AND TIMING OF HEALTH TECHNOLOGY ASSESSMENTS ON MEDICAL DEVICES IN EUROPE
}

\begin{abstract}
Katharina Hawlik
Ludwig Boltzmann Institute for Health Technology Assessment

katharina.hawlik@hta.lbg.ac.at
\end{abstract}

\author{
Patrick Rummel \\ University of Applied Sciences Aalen \\ Claudia Wild \\ Ludwig Boltzmann Institute for Health Technology Assessment
}

Objectives: Strengthening efforts toward better collaboration plays a pivotal role in the assessment of medical devices to reduce overlap and save resources. This study explored the level of duplication in health technology assessments (HTA) of medical devices in Europe and their respective timing in order to identify areas for better collaboration.

Methods: An analysis of European HTA reports of medical devices regarding overlaps in topics and timing in relation to market authorization was performed. We conducted a systematic search in the ADVANCE, Centre for Reviews and Dissemination, Syngerus, and POP databases, complemented by hand searching, to identify HTA reports published between $01 / 2003$ and $07 / 2016$ for a preselected cohort group of ten technologies. We analyzed the number of annual assessments per technology and evaluated activity patterns and timing in undertaking the HTA of the different institutes in Europe.

Results: The results revealed the amount of duplication in the European HTA production: the number of reports per technology ranged from minimum seven to maximum twenty-two over a time-span of 13.5 years. HTA institutes perform assessments at a similar time range within 5 to 10 years following market authorization. The timing of the initial assessment in relation to the granting of the CE-mark varies according to the particular technology.

Conclusion: The findings suggest that efficient collaboration may help to save scarce resources and time of HTA institutes in Europe. Efficient collaboration as such needs to shift the focus beyond the time span of 1 year, and build on each's others work from previous assessments.

Keywords: Medical devices, Health technology assessment, Europe

The market for medical devices (MDs) and diagnostic procedures is one of the fastest growing in health care globally, with Europe one of its biggest customers. 11,000 patent applications for medical technologies were filed at the European Patent Office (EPO) in 2014, approximately twice as many as for pharmaceuticals in the same year (1). Due to the rising costs associated with the introduction of these new medical technologies into European healthcare systems, payers have started to pay more attention to effectiveness and costs of the many novel technologies: health technology assessment (HTA) of medical devices and procedures gained increasing recognition on a European level in recent years.

The challenges of applying HTA for MDs have been widely recognized and underlying reasons discussed (2-5). The unique characteristics of MDs render assessments difficult, for instance, the heterogeneity of products requiring adapted methodologies, and the learning curve of the device users, which might distort effectiveness assessments. Importantly, compared with pharmaceuticals, the amount and qual-

We thank Judit Erdös for supporting the systematic search and Robert Kalcik for data advice and feedback in the completion of this work. Financial support: There are no sources of funding to be reported. Ethical approval: Not required. ity of the available evidence is generally poorer for MDs (6), attributed to weaker regulatory requirements which do not necessitate profound evaluations of effectiveness (7). In Europe, the general evidence requirements even for medium and highrisk MDs focus on the presentation of safety and technical performance studies only (8). Furthermore, the available evidence often lacks relevant and suitable end-points to derive a recommendation or reimbursement decision (5). In May 2017, the European Parliament approved a revised EU regulation to improve the market authorization processes for MDs and, expectedly, the evidence base for decision making (9). The new regulation shall enforce stricter controls of notified bodies and increase transparency and traceability of products. Yet, it remains to be evaluated in future years how the new regulation improves data on safety and effectiveness of novel technologies.

Another major reason for the difficulties assessing medical devices is their rapid, sequential development with stepwise product modifications (3). This iterative innovation poses specific methodological hurdles for HTA practice: while the first version of a device is being assessed, a newer version might already be on the market (5). HTA bodies need to find the appropriate timing for an assessment within the life cycle of the device, also considering the potential impact of the learning curve on the outcome measured. Too early assessments might 
not lead to conclusive recommendations, as sufficient evidence is likely not yet available. Too late assessments, on the other hand, could either delay market access of potentially beneficial technologies or would not be relevant for a country anymore, if reimbursement decisions have already been taken (10).

One approach to address the challenges of the assessment of MDs is increasing the harmonization of methods and cooperation between HTA institutes. Collaborating on a European level can save time and financial resources by avoiding redundancy and improving the timeliness of assessments with appropriate levels of evidence. Accordingly, reducing duplication of efforts and promoting effective use of resources was declared as one of the strategic objectives of the European network for Health Technology Assessment (EUnetHTA: www.eunethta.eu), aiming to create an effective and sustainable network for HTA across Europe (11). Established in 2006, it today involves more than seventy institutions in thirty-two European countries (12). An important milestone toward efficient EU collaboration was the establishment of a joint methodological framework, the HTA Core Model ${ }^{\circledR}$, including a methodological guideline for the assessment of therapeutic medical devices issued in 2015 (12).

Reduction of duplication of work and the timeliness of the HTA assessments are well-recognized problems that need to be addressed in future collaborative efforts of European HTA (13). The EUnetHTA Planned and Ongoing Projects database (POP$\mathrm{Db}$ ) was developed to evaluate the extent of overlap in topics and to identify areas for collaboration (14). In 2014, a range of 10 to 12 percent of the ongoing or planned projects in the POP-Db was identified as identical (same technology and indication), and 30 to 39 percent were on the same technology with similar indications, suggesting considerable potential to collaborate on specific topics (13).

While redundancy and duplication of efforts are widely acknowledged and discussed problems (15), to date the amount of topic overlap has not been evaluated. Furthermore, the timing of the assessments and differences in timing between European institutes have not been studied. Finding the appropriate timing for an assessment becomes more relevant, the more countries are involved, because different healthcare systems set different priorities for HTA needs. This research sought to explore and analyze the amount of duplication in the assessment of MDs in Europe and the timing in relation to market authorization to identify future possibilities toward more efficient collaboration on a European level.

\section{METHODS}

We performed an analysis of European HTA reports on (selected) medium and high-risk MDs published within the last years to estimate the level of duplication and to analyze the timing of HTA reports on MDs in relation to market authorization (time of receiving the CE-mark, Conformité Européenne).
A cohort group of ten MDs with high HTA relevance was selected for the purpose of the analysis using the ADVANCE HTA database (16), a research project that was developed under a grant agreement of the European Commission's Research Framework Programme (EU-FP7/ 2007-13). This database consists of HTA reports conducted from 2004-15 by European HTA institutes, whereby devices and procedures are classified by their taxonomic position (17). This newly developed taxonomic model provides a matrix to distinguish the potential relevance of different product categories for HTA, ranging from high to low relevance. Relevant is thereby defined by the taxonomic position within the matrix and correspond to risk class IIb, III and implantable devices risk class IV. For the purpose of this analysis, MDs with high HTA relevance and high frequency from the year 2014 were chosen. From all HTA reports on MDs conducted in $2014(\mathrm{n}=136)$, only assessments on medium or high-risk and active implantable devices or procedures were collected ( $n=87 ; 64$ percent), and accordingly a balanced sample of ten MDs from risk group IIb $(n=4)$, III $(n=4)$, and IV $(n=2)$ were selected. The cohort group of the selected devices and respective taxonomic positions and risk classes are presented in Table 1.

In addition to the ADVANCE database, a systematic search in the Centre for Reviews and Dissemination (CRD) database, the (commercial) Synergus database and the EUnetHTA POP database was conducted to identify all European HTA reports evaluating the ten devices before and after 2014, within a time span of 13.5 years (January 2003 until July 2016). A hand search was conducted using google scholar, and the respective web sites of European HTA institutes to obtain the reports identified in the databases (final date of data collection July 31 , 2016). The reports were not limited to English language, and not limited to specific national European HTA institutes, but aimed to include regional as well as national HTA assessments of European countries. Identified HTA reports were excluded if they were not available on the website and if identical reports were listed multiple times within the four databases, under different titles or languages. In two cases, an agency published several reports on the same technology at the same time, but reporting different indications. These reports were calculated as one report not to distort the total number of assessments per technology. Because the health service systems of the United Kingdom operate independently, the United Kingdom was analyzed separately as England and Scotland. The dates of market authorization (CE-mark) for each of the ten technologies were identified by a web-based hand search.

We analyzed the number of annual and overall HTA reports per technology, and the number of assessments per HTA institute within the time span of 13.5 years. Additionally, the date of market authorization and CE-mark was compared with the respective timing of the HTA reports of different European HTA institutes. Data were analyzed in R (version 3.4.0) and Microsoft Excel. 


\begin{tabular}{|c|c|c|c|c|c|c|}
\hline Technology & $\begin{array}{l}\text { Taxonomic } \\
\text { position }^{0}\end{array}$ & $\begin{array}{l}\text { Risk } \\
\text { group }\end{array}$ & $\begin{array}{l}\text { lst }^{\text {CE}}- \\
\text { mark }\end{array}$ & $\begin{array}{l}\text { No. of products } \\
\text { (with CE-mark) }\end{array}$ & $\begin{array}{l}\text { Time } \\
\text { range }\end{array}$ & $\begin{array}{l}\text { No. of } \\
\text { HTAs }\end{array}$ \\
\hline Sacral nerve stimulation (SNS) & 32 & IV & 1994 & 2 & $2004-2016$ & 9 \\
\hline Intraoperative radiation therapy (IORT) & 27 & $\| b$ & 1999 & 6 & $2006-2015$ & 7 \\
\hline Robotic surgery (RS) & 27 & $\| \mathrm{lb}$ & 1999 & 2 & $2007-2015$ & 13 \\
\hline High intensity focused ultrasound (HIFU) & 27 & $\| \mathrm{lb}$ & 2000 & 10 & 2003-2014 & 13 \\
\hline $\begin{array}{l}\text { Implantable cardiac resynchronization therapy and } \\
\text { defibrillator (CRT-P/D) }\end{array}$ & 14,32 & IV & 2001 & 8 & $2003-2015$ & 12 \\
\hline Lumbar total disc replacement (LTDR) & 29 & ||| & 2001 & 4 & $2007-2016$ & 8 \\
\hline Drug-eluting stents (DES) & 29 & |l| & 2002 & 12 & $2004-2015$ & 15 \\
\hline Intensity-modulated radiation therapy (IMRT) & 27 & $\| \mathrm{lb}$ & 2002 & 7 & $2003-2015$ & 12 \\
\hline Transcatheter aortic valve implantation (TAVI) & 29 & ||| & 2007 & 5 & $2008-2015$ & 22 \\
\hline MitraClip ${ }^{\circledR}$ & 29 & |l| & 2008 & 1 & $2010-2016$ & 9 \\
\hline Total no. of reports & & & & & & 120 \\
\hline
\end{tabular}

Note. No., number, number of identified HTA reports by technology from January 2003- July 2016, Time range from first to latest assessment.

aHenschke C., Panteli D., Perleth M. \& Busse R. Taxonomy of medical devices in the logic of health technology assessment. Int J Technol Assess Health Care. 2015;31:324-330. bEuropean Parliament and Council of the European Union. Regulation (EU) 2017/745 of the European Parliament and of the Council of 5 April 2017 on medical devices, amending Directive 2001/83/EC, Regulation (EC) № 178/2002 and Regulation (EC) No 1223/2009 and repealing Council Directives 90/385/EEC and 93/42/EEC. L117, 2017

\section{RESULTS}

\section{Collected Data on HTA Reports and HTA Institutions}

We identified 120 HTA reports on the ten preselected MDs to be included in the analysis, originating from twenty-eight European HTA institutes of sixteen countries. The twenty-eight institutes were assessing at least one of the ten technologies once or several times within the time span from January 2003 to July 2016, when the final search was completed. Table 1 shows the total number of assessments per technology and the respective time range.

\section{Overlap in Choice of Topics within 1 Year}

2014 was designated as the baseline year for the selection of the cohort group and accordingly the year where most assessments of the ten technologies were conducted, in total twenty-one assessments. Ten countries were assessing the technologies; fifteen HTA institutes conducted the assessments. Half $(n=5)$ of the selected technologies were assessed twice or more than twice, with a maximum of five assessments for transcatheter aortic valve implantation (TAVI) stemming from four European countries. In Spain, two HTA institutes conducted assessments on TAVI in 2014.

\section{Overlap in Assessments within the Time Span of 13 Years}

The analysis of the number of assessments for one technology over a time span of several years depicts the potential redundancy in European HTA assessments of medical devices.
From January 2003 until July 2016, the number of reports per technology or procedure ranged from seven for intraoperative radiation therapy (IORT) to twenty-two for TAVI. Figure 1 depicts the cumulative number of assessments per technology from 2003 to 2016. To compare newer and older technologies with each other, the number of assessments per years since acquiring CE-mark is presented.

Technologies that have been granted market authorized in an earlier period are expected to have more assessments than those, which recently acquired the first CE-mark. However, TAVI was the most frequently assessed technology from the cohort group, with overall twenty-four HTA reports stemming from thirteen HTA institutes and ten European countries, despite it being one of the most recent technologies acquiring the CE-mark in 2007. MitraClip ${ }^{\circledR}$, which gained market authorization 1 year later in 2008, was assessed nine times within the time span of 6 years by seven HTA institutes and six countries. It was first assessed in 2010, and since then has been assessed annually by at least one country, three times in 2012 and twice in 2015. All but one technology, namely IORT, were assessed by more than six countries; more than half of the selected technologies were assessed by seven countries or more (Table 2). Apart from TAVI, drugeluting stents (DES), CE-mark in 2002, and high-intensity focused ultrasound (HIFU), CE-mark in 2000, were evaluated by the most countries, by nine and eight countries, respectively. For each of the two technologies, the assessments stem from twelve different institutes, indicating in-country overlaps. 


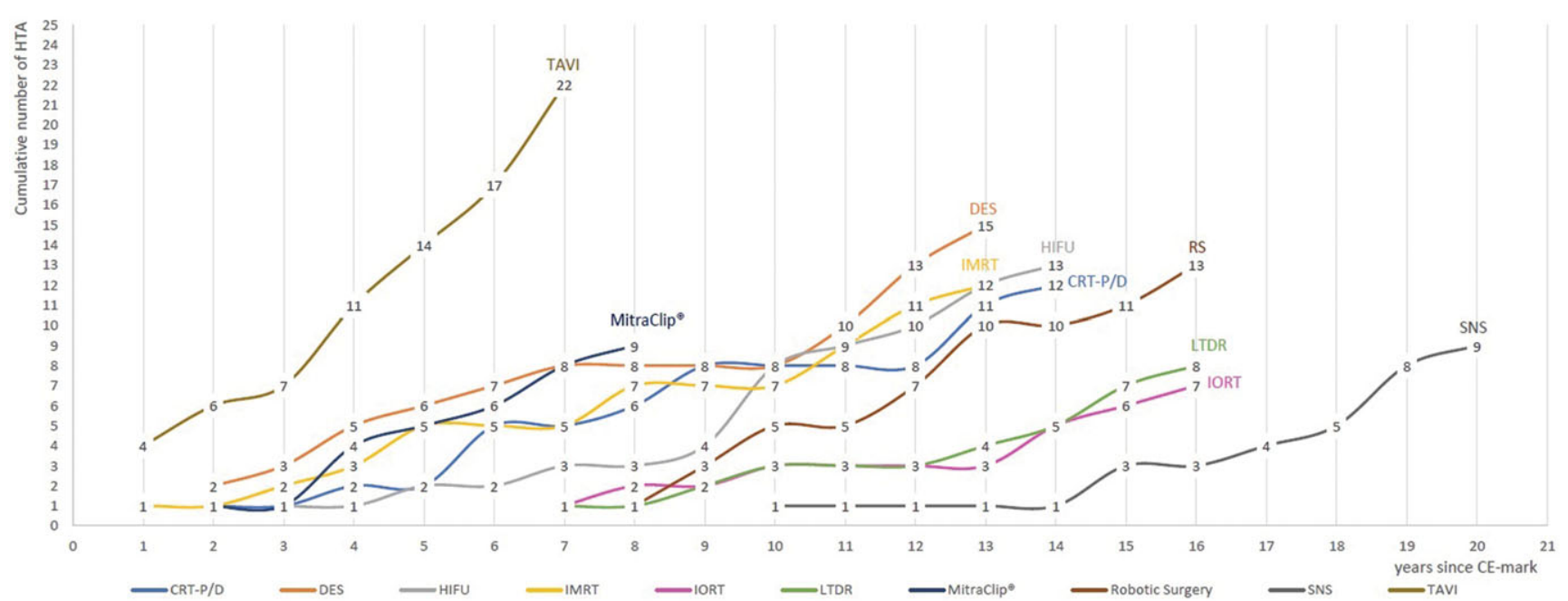

Figure 1. Cumulative number of HTA reports January 2003 to July 2016, from year since CE-mark.

\section{Timing of HTA Assessments in Relation to CE-Mark}

To evaluate differences in the timing of the assessments, the CE-mark of the first product was compared with the timing of the initial HTA assessment. The dot plot in Figure 2 shows the timing of the reports (red dots) in relation to the CE-mark (indicated by the black line), whereby reports that were conducted closer to the CE-mark are marked with darker dots. Only those countries that assessed the technology are shown. The countries are organized according to the proximity in timing of the report in relation to CE-marking, the first assessor countries are found in the top line. The dot plots show no clear pattern of early and late assessors: first and last assessors are varying from technology to technology. There are some countries that tend to assess some technologies earlier than others do, such as the England, France, Spain, and Austria, which are among the first three assessors of more than four technologies. However, this indicates that timing of the assessment seems to depend on the technology rather than on the country. Additionally, the graphs (Figures 1 and 2) show that depending on the interest in one technology more assessments are conducted, by more countries, and these are performed closer to CE-marking (e.g., for TAVI and DES).

To analyze the potential patterns of late or early assessors for the basket of ten technologies, the overall timing of all assessments conducted in one country are depicted in the boxplot in the bottom right corner of Figure 2. The boxplot shows the range of timing of the assessments and the band inside the boxes is the median time of assessments. The wide spread of the boxes indicates the high heterogeneity in timing of the assessments within the countries. Comparing countries with each other, the medians of all countries but the Netherlands and Sweden range between 5 and 10 years post CE-Mark, showing that the majority of reports are conducted within 5 to 10 years following CE-mark authorization. In four countries, the assessments' median time since market authorization was below 7.5 years: Austria, Belgium, Finland, and Scotland. For completeness, Norway, Ireland, Lithuania, and Switzerland are shown in the boxplot, however, because there was only one or two HTA reports included in the study, these results could not be considered.

To summarize the results of the two graphic representations, it seems as if there is no straight pattern of early or late assessors. On the contrary, the timing of the assessments between different countries seems to be similar, with high heterogeneity in relation to the technology. Technologies that are evaluated by many countries tend to be assessed earlier, while technologies with overall fewer assessments seem to be assessed later in the life cycle.

\section{DISCUSSION}

Though the findings are limited to the cohort of the selected ten technologies and do not reflect the total number of HTA reports on medical technologies in Europe, some notable observations were made.

\section{Overlap and Redundancy}

The analysis of the number of assessments on ten technologies over a time span of 13.5 years unrevealed the potential redundancy of HTA on MDs in Europe. Multiple HTA reports on the same technology or procedure are conducted within the same year and over several years. In 2014, the ten selected technologies were assessed twenty-one times, with a maximum of five reports for one technology. These findings are more pronounced when looking at a time span of several years, where assessments per technology range from seven to twenty-two reports. Additionally, we noted some in-country redundancy, particularly for HTA institutes in Spain where identical technologies were assessed by up to three different institutes. 
Hawlik et al.

Table 2. HTA on Ten Selected Technologies: Countries and HTA Agencies

\begin{tabular}{|c|c|c|c|c|}
\hline Country & Agencies & №. of Tech ${ }^{a}$ & Technologies & №. of $H T A s^{b}$ \\
\hline Austria (AT) & LBI-HTA & 8 & DES, HIFU, IORT, LTDR, MitraClip ${ }^{\circledR}$, RS, SNS, TAVI & 14 \\
\hline Belgium (BE) & KCE & 7 & CRT-P/D, DES, IMRT, LTDR, RS, TAVI & 10 \\
\hline Croatia (HR) & AAZ & 2 & IMRT, TAVI & 2 \\
\hline Finland (FI) & FinOHTA & 2 & RS, TAVI & 2 \\
\hline France (FR) & $\begin{array}{l}\text { CEDIT } \\
\text { HAS }\end{array}$ & 9 & $\begin{array}{l}\text { MitraClip }{ }^{\circledR}, \text { RS } \\
\text { DES, HIFU, IMRT, IORT, LTDR, MitraClip }{ }^{\circledR} \text {, RS, SNS, TAVI }\end{array}$ & 16 \\
\hline Germany (DE) & $\begin{array}{l}\text { IQWIG } \\
\text { G-BA } \\
\text { DIMDI }\end{array}$ & 2 & $\begin{array}{l}\text { HIFU, DES } \\
\text { HIFU } \\
\text { DES }\end{array}$ & 4 \\
\hline Ireland (IE) & HIQA & 1 & RS & 1 \\
\hline Italy (IT) & $\begin{array}{l}\text { AGENAS } \\
\text { ASSR }\end{array}$ & 7 & $\begin{array}{l}\text { CRT-P/D, HIFU, LTDR, TAVI } \\
\text { DES, IMRT, RS, TAVI }\end{array}$ & 9 \\
\hline Lithuania (LT) & VASPVT & 1 & SNS & 1 \\
\hline Netherlands (NL) & ZIN & 3 & HIFU, SNS, TAVI & 4 \\
\hline Norway (NO) & NIPHNO (NOKC) & 1 & DES & 1 \\
\hline Poland (PL) & AOTMIT & 2 & HIFU, MitraClip $\left.{ }^{(}\right)$ & 2 \\
\hline Spain (ES) & $\begin{array}{l}\text { AETSA } \\
\text { AVALLA-T } \\
\text { AQUAS OSTEBA } \\
\text { UETS }\end{array}$ & 10 & $\begin{array}{l}\text { CRT-P/D, DES, HIFU, IMRT, IORT, LTDR, RS IMRT, IORT, TAVI } \\
\text { HIFU, SNS } \\
\text { IMRT, MitraClip }{ }^{\circledR} \text {, TAVI } \\
\text { CRT-P/D, DES, HIFU, RS }\end{array}$ & 26 \\
\hline Sweden (SE) & $\begin{array}{l}\text { Metodrådet i SSR } \\
\text { SBU } \\
\text { HTA-centrum VGR }\end{array}$ & 5 & $\begin{array}{l}\text { LTDR } \\
\text { CRT-P/D, DES } \\
\text { DES, MitraClip }{ }^{\circledR}, \text { SNS }\end{array}$ & 7 \\
\hline Switzerland (CH) & SMB & 2 & CRT-P/D, LTDR & 2 \\
\hline England (ENG) & $\begin{array}{l}\text { NICE } \\
\text { NIHR }\end{array}$ & 8 & $\begin{array}{l}\text { CRT-P/D, DES, HIFU, LTDR, SNS, TAVI } \\
\text { CRT-P/D, HIFU, IMRT, RS, TAVI }\end{array}$ & 15 \\
\hline Scotland (SCT) & HIS & 3 & CRT-P/D, MitraClip ${ }^{\circledR}$, TAVI & 4 \\
\hline
\end{tabular}

Note. AAZ, Agency for Quality and Accreditation in Health Care and Social Welfare; AETSA, Andalusian HTA Agency; AGENAS, Agenzia Nazionale per i Servizi Sanitari Regionali; AOTMit, Agency for Health Technology Assessment and Tariff System; ASSR, Regione Emilia Romagna; Regional Agency for Health and Social Care, AVALLA-T, Galician Agency for HTA; AQuAs, Agència de Qualitat i Avaluació Sanitàries de Catalunya; CEDIT, Comité d'Evaluation et de Diffusion des Innovations Technologiques; DIMDI, German Institute of Medical Documentation and Information; FinOHTA, Finnish Office for Health Technology; G-BA, Gemeinsame Bundesausschuss; HAS, Haute Autorité de santé; HIQA, Health Information and Quality Authority; HIS, Healthcare Improvement Scotland; IQWIG, Institute for Quality and Efficiency in Health Care; KCE, Belgian Health Care Knowledge Centre; LBI-HTA, Ludwig Boltzmann Institute for Health Technology Assessment; Metodrådet i SSR, Regionala metodrådet; sydöstra sjukvårdsregionen; NICE, National Institute for Health and Care Excellence; NIHR, National Institute for Health research; NIPHNO (formerly NOKC) Norwegian Institute of Public Health; No., number; OSTEBA, Basque Office for Health Technology Assessment; SBU, Swedish Agency for Health Technology Assessment; SMB, Swiss Medical Board; tech, technology; UETS, Consejería de Sanidad; VASPVT, State Health Care Accreditation Agency under the Ministry of Heath of the Republic of Lithuania; HTA-centrum VGR, Västra Götalandsregionen; ZIN, National Health Care InstituteAssessment

aNumber of assessed technologies.

${ }^{b}$ Number of HTA reports conducted in a country.

Some technologies were assessed multiple times by the same institute, indicating that these assessments were updates of earlier reports, potential reasons being new evidence becoming available, additional indications for a technology or alterations in the technology itself. A limitation of this work is that we focused on the technology itself, rather than analyzing the specific indications for each technology. While the included reports shared common indications, some additional in- dications might have evolved along the life cycle of a device. Furthermore, reports may be adaptions of jointly produced EUnetHTA assessments, exemplifying a positive sign for collaboration rather than duplication.

However, this was the case for only one report on MitraClip $^{\circledR}$ (18). Thus, clearly, not all reports can be considered redundant, as they might be valuable updates of earlier assessments, differ in context, comparators, outcomes or 

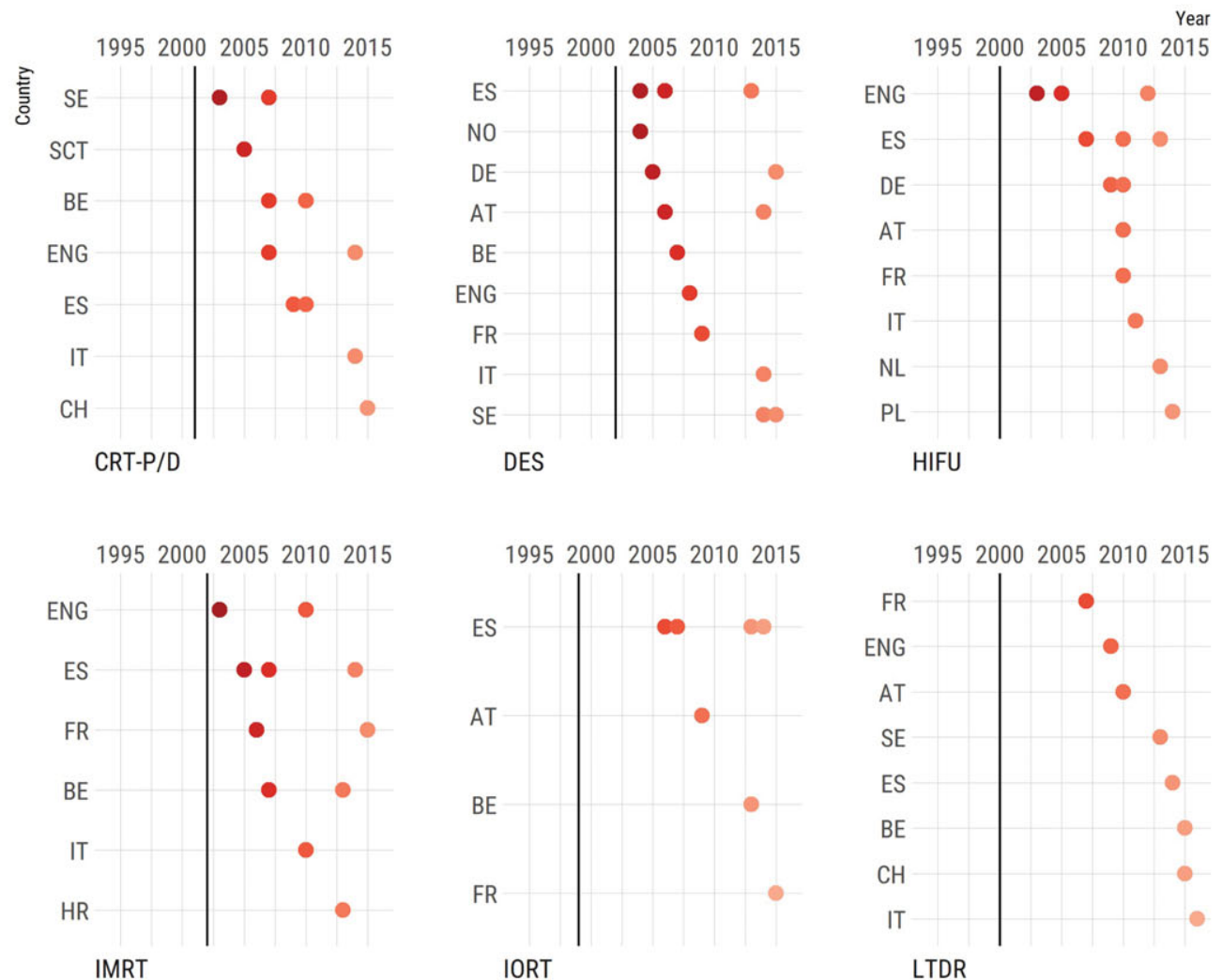

| CE Mark
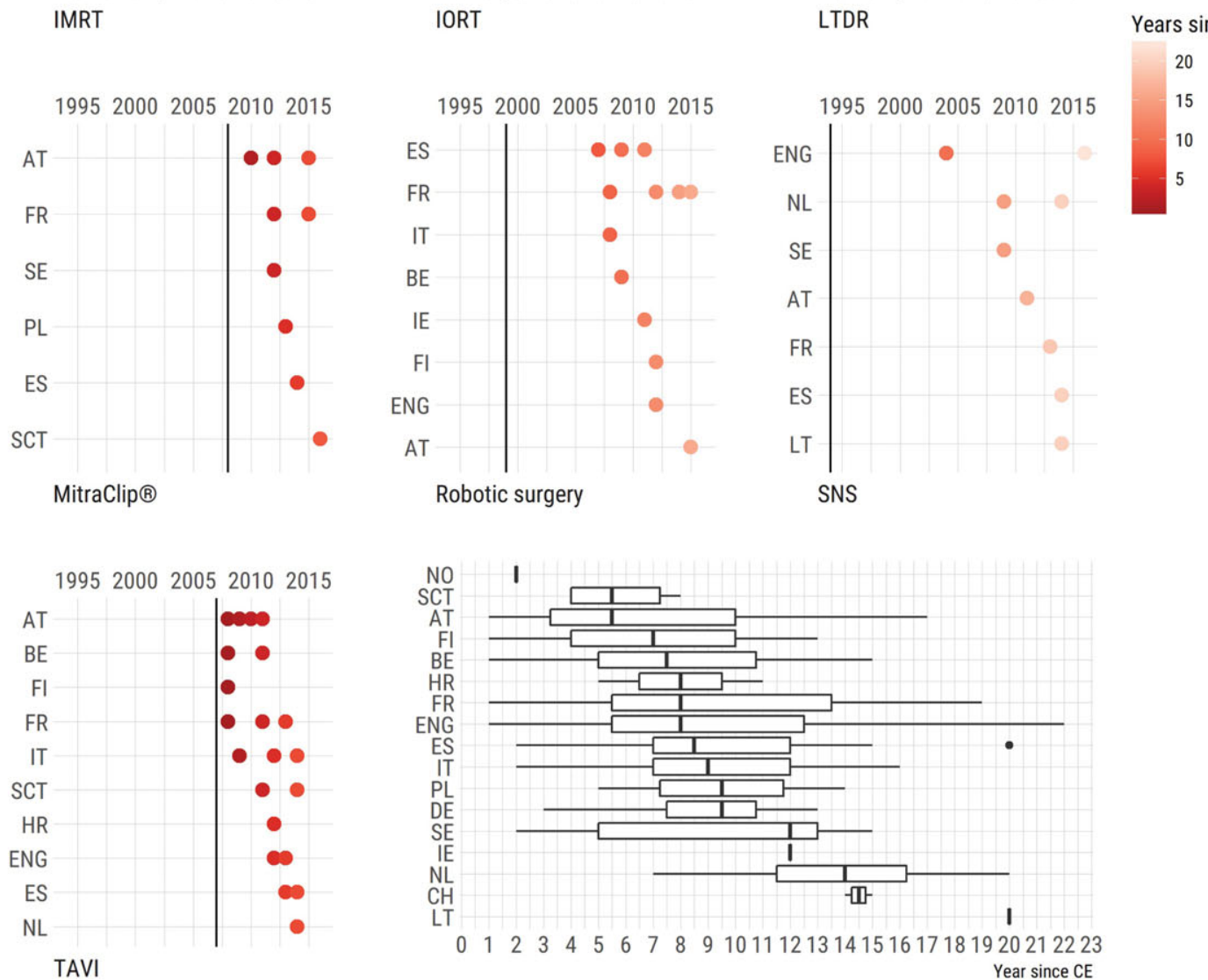

Figure 2. Timing of HTA assessments in relation to market- authorization (CE-mark). 
organizational aspects, or include new indications for a technology. Conclusions on duplication and redundancy must be considered in the context of these limitations. Yet, our findings of the overlap in topics over a short period of time indicate that considerable redundancy of reports is very plausible, especially for those reports that have been conducted in a shorter time span of a few years. For example, DES was assessed seven times within 3 years (2013-15) by five countries; an overlap in the content of these assessments in terms of best available evidence is very likely. While, over a longer period, repeated assessments are likely to be updates of new evidence or indications, the high number of reports over a shorter period suggest a potential redundancy.

We did not analyze the similarity of content and studies included in the HTA reports since reports were written in multiple different languages, and not all of the reports provided information on the included studies. A further content analysis of HTAs on the same technology comparing the research questions, methods used to answer these, and the scope of the assessments is the logical follow-up research to gain further insights into the actual level of redundancy. We encourage future research to also conduct an analysis of levels of evidence within HTA reports (7) and evaluate whether there is a link between new evidence available and the timing for updates of certain assessments.

\section{Timeliness of Assessments}

Timing of the assessments has been identified as a crucial factor for collaboration (19). Hence, we aimed to analyze the alterations in overall assessment timing of HTA agencies. We could not identify a pattern of early or late assessors; by contrast, it seems to depend on the type of technology rather than on the country at which point in time the initial assessment is conducted. There is high heterogeneity between the specific technologies: while some technologies, such as TAVI and MitraClip ${ }^{\circledR}$ are assessed soon after the first product gained market authorization, other assessments were evaluated much later.

When comparing the timing of the initial assessments between countries, we observed that assessments happen at similar time ranges; the majority of institutes assess technologies in between 5 and 10 years following market authorization. The findings suggest that efforts toward better collaboration should focus on a timing of five years after market authorization to make assessments most relevant for national priorities. European Horizon Scanning Projects could facilitate this process, by identifying relevant technologies at an early stage to find the appropriate timing for the assessments (20).

The ten different technologies chosen for this study represent only a small percentage of the devices on the European market. The small sample size is a limitation of this study, because, evidently, ten technologies are not enough to generalize on the overall timing of the assessments and on early or late assessors. However, from the chosen sample a pattern emerged showing that there are similarities in timing between different countries and that these depend on the technologies. These results, although initial, provide a first systematic analysis of differences in timing and offer a promising prospect for future collaboration, as similarities in timing priorities between countries could facilitate collaboration. For future research, it would be worthwhile to analyze potential differences in timing in between types of technologies and risk classes to identify reasons why certain technologies are assessed earlier than others.

\section{European Data Base on Medical Devices}

The variances in the nomenclature of the technologies used in different countries and languages, their use for multiple indications and the various products and brand names render a comprehensive search for assessments on MDs particularly difficult. To date, there is no comprehensive database including all conducted HTA reports on MDs in Europe. The database developed under the FP7 project ADVANCE delivers initial progress toward a European collection of HTA reports on medical technologies (16). In 2015, the project was finalized and there are currently no plans to prolong or sustain it for the future. However, only approximately 40 percent of the 120 reports included in the study were identified by use of the ADVANCE database, and Synergus, CRD, and POP database, as well as an additional hand searching was needed to get a more comprehensive sample of European HTA reports on MDs. The meticulous search in four different databases allowed us to identify a representative number of reports on the selected technologies, however, given the variances in the nomenclature of the technologies, it is possible that we have missed some and underestimated the results.

Similarly, there are no official published sources on CEmarked products to specify the time of market entry. For the information on the year of the market authorization, we had to rely on company announcements, investor reports and news articles on marketed products.

One key objective of the new regulation on MDs is the introduction of a European database on MDs (EUDAMED) that should increase transparency and collate information on marketed devices, conformity assessments, and clinical investigations. Furthermore, the conception of a common nomenclature is envisioned (9), which could substantially improve monitoring of different HTA-, and reimbursement activities in Europe.

\section{Prospects for Collaboration}

Collaborative efforts on HTA on MDs have substantially increased in recent years. Several initiatives have evaluated barriers for the assessments of MDs, came up with a classification system and developed methodological guidance $(4 ; 13 ; 17)$. The EUnetHTA CoreModel ${ }^{\circledR}$ provides the methodological framework to facilitate and enhance sharing of results and national 
uptake of reports and the POP database provides a list of planned and ongoing projects to align work plans $(12 ; 14)$. Despite these efforts, there is still considerable overlap of assessments, as presented in this study, and the national uptake of EUnetHTA reports progresses slowly.

Not only methodology but also language is still a major barrier for collaboration (19): Although some countries have started to completely convert to English as their primary language for HTA reports, such as Austria and Belgium, the majority of countries still write reports in their national language and would only include an English executive summary. The HTA reports identified in this research were conducted in ten different languages.

One possible way to use the available resources more efficiently could be clustering of HTA institutes with similar work profiles. Within this study, we noticed a difference in countries' HTA activities, whereby some countries and agencies assessed almost all selected technologies, some of them even several times along the evolvement of evidence and along the life cycle of the device, updating earlier assessments. Countries and agencies that assess similar technologies might be candidates for collaborating in future European joint assessments or create interest and activity clusters. Thereby, contextualization of the reports to ensure national relevance is a vital prerequisite, as well as adherence to agreed quality standards.

Importantly, whether as collaborative assessments of EUnetHTA or as cluster of HTA institutes with specific work profiles, the findings of this research suggests that institutes need to extend collaboration beyond the period of one year, and build on each other's work of previous years. Today, collaboration seems most efficient five years following market authorization of a product. Provided that the recent regulatory changes result in sufficient evidence becoming available earlier, this time frame might be closer to market authorization in future years.

\section{CONCLUSION}

The considerable amount of duplication shows that there is room for improving collaboration on a European level: be it by building on each other's HTA reports in successive years or collaborating within the same year within joint assessments. The EUnetHTA Core Mode $l^{\circledR}$ provides a framework to build on each other's assessments and facilitates methodological alignment of reports. The new MD regulation nurtures hope for improved evidence requirements and a transparent database to better coordinate assessments and retrieve valuable market information. In light of these positive developments of recent years, collaboration of HTA institutes in Europe now needs to shift the focus of collaborative efforts beyond one year, and emphasize building on each other's work.

\section{CONFLICTS OF INTEREST}

The authors declare that they have nothing to disclose.

\section{REFERENCES}

1. The European Medical Technology industry in figures 2015. 2015. MedTech Europe. http://www.medtecheurope.org/sites/default/files/ resource_items/files/MEDTECH_FactFigures_ONLINE3.pdf (accessed August 1, 2017).

2. Fuchs S, Olberg B, Panteli D, Busse R. Health technology assessment of medical devices in Europe: Processes, practices, and methods. Int $J$ Technol Assess Health Care. 2016;32:246-255.

3. Fuchs S, Olberg B, Panteli D, Perleth M, Busse R. HTA of medical devices: Challenges and ideas for the future from a European perspective. Health Policy. 2017;121:215-229.

4. Tarricone R, Torbica A, Drummond M. Key recommendations from the MedtecHTA Project. Health Econ. 2017;26:145-152.

5. Campbell B, Dobson L, Higgins J, et al. A new health technology assessment system for devices: The first five years. Int J Technol Assess Health Care. 2017;33:19-24.

6. Campbell B, Knox P. Promise and plausibility: Health technology adoption decisions with limited evidence. Int J Technol Assess Health Care. 2016;32:122-125.

7. Krüger LJ, Evers SMAA, Hiligsmann M, Wild C. Divergent evidence requirements for authorization and reimbursement of high-risk medical devices - The European situation. Health Policy Technol. 2014;3:253263.

8. Krüger LJ, Wild C. Evidence requirements for the authorization and reimbursement of high-risk medical devices in the USA, Europe, Australia and Canada: An analysis of seven high-risk medical devices. 2013. http://eprints.hta.lbg.ac.at/1017/1/HTA-Projektbericht_Nr.73.pdf (accessed September 5, 2017).

9. European Parliament and Council of the European Union. Regulation 2017/745 of the European Parliament and of the Council of 5 April 2017 on medical devices, amending Directive 2001/83/EC, Regulation (EC) No 178/2002 and Regulation (EC) No 1223/2009 and repealing Council Directives 90/385/EEC and 93/42/EEC. 2017. http://eur-lex.europa.eu/ legal-content/EN/TXT/?uri=OJ:L:2017:117:TOC (accessed August 2, 2017).

10. Schnell-Inderst P, Mayer J, Lauterberg J, et al. Health technology assessment of medical devices: What is different? An overview of three European projects. Z Evid Fortbild Qual Gesundhwes. 2015;109:309318.

11. Kristensen FB, Lampe K, Chase DL, et al. Practical tools and methods for health technology assessment in Europe: Structures, methodologies, and tools developed by the European network for Health Technology Assessment, EUnetHTA. Int J Technol Assess Health Care. 2009;25: 1-8.

12. Kristensen FB, Lampe $\mathrm{K}$, Wild $\mathrm{C}$, et al. The HTA Core Model ${ }^{\circledR}$ - 10 years of developing an international framework to share multidimensional value assessment. Value Health. 2017;20:244250.

13. Nachtnebel A, Mayer J, Erdos J, et al. [HTA goes Europe: European collaboration on joint assessment and methodological issues becomes reality]. Z Evid Fortbild Qual Gesundhwes. 2015;109:291299.

14. Wild C, Erdös J, Warmuth M, et al. Planned and ongoing projects (POP) database: Development and results. Int J Technol Assess Health Care. 2014;30:497-503.

15. Garrido MV. Health technology assessment and health policy-making in Europe: Current status, challenges and potential. Geneva: WHO Regional Office Europe; 2008.

16. Advancing and strengthening the methodological tools and policies relating to the application and implementation of Health Technology Assessment (HTA). 2007-2013. LSE Health. http://www.advance-hta.eu/ index.php (accessed August 2, 2017). 
Hawlik et al.

17. Henschke C, Panteli D, Perleth M, Busse R. Taxonomy of medical devices in the logic of health technology assessment. Int $J$ Technol Assess Health Care. 2015;31:324-330.

18. Healthcare Improvement Scotland. MitraClip ${ }^{\circledR}$ transcatheter mitral valve repair system - Evidence note 58. 2016. www.healthcareimprove mentscotland.org/his/idoc.ashx?docid=5c20fc01-99be-48d5-a6e6-7756 60de8d18\&version=-1 (accessed October 29, 2017).

19. Huić M, Nachtnebel A, Zechmeister I, Pasternak I, Wild C. Collaboration In health technology assessment (EUnetHTA Joint Action, 2010 2012): Four case studies. Int J Technol Assess Health Care. 2013;29:323330.

20. Nachtnebel A, Breuer J, Willenbacher W, et al. Looking back on 5 years of Horizon Scanning in Oncology. Int J Technol Assess Health Care. 2016;32:54-60. 